\begin{tabular}{|c|c|c|}
\hline ح & $\begin{array}{c}\text { Klinikal Sains } 9(1)(2021) \\
\text { JURNAL ANALIS KESEHATAN } \\
\text { KLINIKAL SAINS }\end{array}$ & KLINKALSAINS \\
\hline $\begin{array}{l}\text { UNIVERSITAS } \\
\text { ABDURRAB }\end{array}$ & http://jurnal.univrab.ac.id/index.php/klinikal & 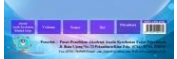 \\
\hline
\end{tabular}

\title{
ANALISA TINGKAT KERACUNAN LOGAM BERAT Pb PADA TUKANG BECAK DAN PEDAGANG ASONGAN DI JALAN KAPTEN MUSLIM MEDAN
}

\author{
Nova Florentina Ambarwati, Eka Margaretha Sinaga, Erdina Gultom \\ Program Studi D3 Analis Kesehatan, Fakultas Farmasi \& Ilmu Kesehatan, \\ Universitas Sari Mutiara Indonesia \\ Jl. Kapt. Muslim No. 79, Medan \\ nova.fio82@gmail.com
}

\begin{tabular}{l}
\hline Info Artikel \\
\hline Sejarah Artikel: \\
Diterima Agustus 2020 \\
Disetujui Juni 2021 \\
Dipublikasikan Juni 2021 \\
Keywords: \\
Lead (Pb), pedicab drivers, \\
street vendors, hair, AAS
\end{tabular}

street vendors, hair, AAS

\begin{abstract}
Abstrak
Timbal $(\mathrm{Pb})$ merupakan salah satu jenis logam berat berbahaya yang bersifat toksik bagi tubuh manusia. Timbal terdapat di udara dalam bentuk pencemaran udara yang dihasilkan oleh bahan bakar kendaraan bermotor. Menurut WHO tahun 1995 tingkat kadar timbal di tubuh manusia dibagi menjadi 3 tingkatan yaitu, rendah $(<10 \mathrm{ppm})$, sedang $(10-20 \mathrm{ppm})$, ataupun tinggi $(>20 \mathrm{ppm})$ sesuai kategori pencemaran. Tukang becak dan pedagang asongan sangat sering berada di jalan raya, yang tentunya mereka akan sangat sering terpapar oleh asap kendaraan yang mengandung $\mathrm{Pb}$. Penelitian ini bertujuan untuk mengetahui tingkat pencemaran kadar $\mathrm{Pb}$ pada rambut tukang becak dan pedagang asongan yang berada di sekitaran Jalan Kapten Muslim Medan. Dari keseluruhan populasi yang berjumlah 12 tukang becak dan 8 pedagang asongan diambil masing-masing sampel sebanyak 4 (empat) dari masing-masing rambut dari tukang becak dan pedagang asongan dengan metode acak sederhana, kemudian dilanjutkan dengan pemeriksaan menggunakan alat SSA (Spektrofotometer Serapan Atom). Dari hasil penelitiaan secara keseluruhan diperoleh bahwa 1 (satu) diantaranya pada tingkat keracunan tinggi (20,138 ppm), kemudian 2 (dua) pada tingkat keracunan sedang (10,697 - 16,69 ppm), dan 5 (lima) lainnya pada tingkat keracunan rendah $(0,862 \approx 4,533 \mathrm{ppm})$. Hal ini menunjukkan bahwa hampir seluruh tukang becak dan pedagang asongan di sekitaran jalan Kapten Muslim Medan sudah keracunan logam berat $\mathrm{Pb}$ dalam tubuhnya.

Kata Kunci: Timbal $(\mathrm{Pb})$, tukang becak, pedagang asongan, rambut, SSA
\end{abstract}

\begin{abstract}
Lead $(\mathrm{Pb})$ is a dangerous heavy metal that is toxic for human bodies. Lead can be found in the air in the form of air pollution which is produced by the fuel of motor vehicles. According to WHO, in 1995, the level of lead inside the human body can be divided into three levels which are, low $(<10 \mathrm{ppm})$, moderate $(10-20 \mathrm{ppm})$, otherwise high (>20ppm) according to the category of pollution. A pedicab driver and a hawker who frequent the street will surely very often be exposed to vehicle fumes which contains lead $(\mathrm{Pb})$. This experiment is aimed to find out the level of $\mathrm{Pb}$ in the hair of pedicab drivers and hawkers around Kapten Muslim Street, Medan. From the total population of 12 pedicab drivers and 8 hawkers, 4 (four) samples of each hair were taken from pedicab drivers and hawkers using a simple random method, and then continued with an examination using AAS (Atomic Absorption Spectrophotometer). From the result of the experiment, overall obtained that 1 (one) out of the rest is within the high level of toxicity $(20,138$ ppm), and then 2 (two) within the moderate level of toxicity (10,697 - 16,69 ppm), and 5 (five) others within the low level of toxicity $(0,862 \approx 4,533 \mathrm{ppm})$. This shows that almost all pedicab drivers and street vendors around the Kapten Muslim
\end{abstract}


Nova Florentina Ambarwati, Eka Margaretha Sinaga, Erdina Gultom / Jurnal Analis Kesehatan Klinikal Sains 9 (1) (2021)

Street, Medan are already poisoned with heavy metal, $\mathrm{Pb}$, inside their bodies.

Keywords: Lead $(\mathrm{Pb})$, pedicab drivers, street vendors, hair, $A A S$

(C) 2021 Universitas Abdurrab

Alamat korespondensi:

ISSN 2338-4921

Jl. Kapt. Muslim No. 79, Medan

E-mail: nova fio82@mail.com

\section{PENDAHULUAN}

Kesibukan yang terjadi di jalan raya dipastikan memberi kontribusi yang besar terhadap pencemaran udara ambien daerah tersebut. Meningkatnya penggunaan kendaraan bermotor akan sangat mempengaruhi jumlah pelepasan sisa pembakaran ke atmosfer. Timbal yang mencemari udara dapat berasal dari sisa pembakaran bahan aditif bensin dari kendaraan bermotor. Timbal yang berupa partikel di udara berasal dari sumber- sumber lain seperti pabrik alkil $\mathrm{Pb}$ dan $\mathrm{Pb}$ oksida, pembakaran arang, bensin dan lain-lain (Kusumawati, 2013).

Secara umum, dampak negatif pencemaran timbal $(\mathrm{Pb})$ sangat tinggi terhadap kelompok masyarakat yang sering dan lama kontak terhadap sumber pencemaran timbal $(\mathrm{Pb})$ yang disebut sebagai kelompok masyarakat risiko tinggi (high risk). Kelompok tersebut antara lain : polisi lalu lintas, tukang becak, disekitar terminal, petugas jalan tol, penjualan Koran, dan pedagang asongan. lingkup kerja yang kontak langsung dengan asap kendaraan dan jam kerja yang umumnya seharian terpapar polusi memungkinkan terjadinya penumpukan timbal dalam tubuh. Kandungan timbal $(\mathrm{Pb})$ dalam jaringan tubuh seseorang dipengaruhi oleh jenis jaringan, salah satunya adalah rambut. Rambut merupakan jaringan yang berada di luar tubuh, sehingga rambut kontak langsung dengan polusi udara, selain itu timbal juga dapat masuk melalui inhalasi dimana terbawa kedalam darah dan menyebar keseluruh tubuh (Suryadarma, 2005).

Timbal $(\mathrm{Pb})$ dan senyawanya masuk ke dalam tubuh manusia terutama melalui saluran pernafasan dan saluran pencernaan, sedangkan absorbsi melalui kulit sangat kecil sehingga dapat diabaikan. $\mathrm{Pb}$ yang diabsorbsi diangkut oleh darah ke organ-organ tubuh, dimana sebanyak $95 \% \mathrm{~Pb}$ dalam darah diikat oleh eritrosit. Ekskresi $\mathrm{Pb}$ melalui beberapa cara, yang terpenting adalah melalui ginjal dan saluran cerna (Ardyanto, 2005). Akumulasi Pb dalam tubuh dapat di dideteksi dari darah, tulang, dan rambut. Pada rambut, $\mathrm{Pb}$ terikat pada gugus sulfihidril sehingga kandungan timbal pada rambut dapat dijadikan indikator pencemaran timbal (Handari, 2017).

Kandungan timbal $(\mathrm{Pb})$ dalam jaringan tubuh seseorang dipengaruhi oleh jenis jaringan, salah satunya adalah rambut.Rambut merupakan jaringan yang berada di luar tubuh, sehingga rambut kontak langsung dengan polusi udara, selain itu timbal juga dapat masuk melalui inhalasi dimana terbawa kedalam darah dan menyebar keseluruh tubuh (Suryadarma, 2005). 
Nova Florentina Ambarwati, Eka Margaretha Sinaga, Erdina Gultom / Jurnal Analis Kesehatan Klinikal Sains 9 (1) (2021)

Menurut WHO (World Health Organization) tahun 1995 Tentang Tingkat Kadar Keracunan $\mathrm{Pb}$ di Tubuh Manusia, terbagi atas 3 (tiga) tingkatan yaitu kategori tingkat keracunan $\mathrm{Pb}$ yang rendah (<10 ppm), sedang (10-20 ppm), dan tinggi (>20ppm). Maka tujuan dari penelitian ini adalah untuk mengetahui tingkat keracunan $\mathrm{Pb}$ pada tukang becak dan pedagang asongan yang berada di sekitaran Jalan Kapten Muslim Medan, yang sehari-harinya sangat padat kendaraan bermotor.

Di kota Medan, jalan Kapten Muslim merupakan salah satu jalur yang padat kendaraan. Adanya pasar tradisional yang sangat ramai di sekitaran jalan ini, membuat banyak tukang becak yang beroperasi di sana. Selain itu terdapat juga simpang perempatan jalan menuju kota Binjai dan Deli Serdang, membuat banyak kendaraan yang melewatinya. Tidak heran banyak juga dijumpai pedagang asongan yang berjualan di pinggir jalan ataupun di simpang lampu merah. Para tukang becak dan pedagang asongan di sekitaran jalan Kapten Muslim rata-rata berada di jalan raya mulai pagi sampai sore (10-12 jam). Banyak dari mereka juga tidak menggunakan pelindung diri seperti topi dan masker. Tentunya mereka sangat beresiko terpapar oleh bahaya timbal $(\mathrm{Pb})$

\section{METODE}

Metode pengambilan sampel dalam penelitian ini adalah secara acak sederhana, dimana dari masing-masing kelompok tukang becak dan pedagang asongan diambil 4 (empat) orang yang nantinya akan diambil sampel rambut mereka. Setelah itu dilakukan persiapan sampel, destruksi dan Analisa kadar $\mathrm{Pb}$ dengan menggunakan alat Spektrofotometer Serapan Atom (SSA) di Laboratorium Kesehatan Daerah Provinsi Sumatera Utara yang beralamat di Jalan Willem Iskandar, Medan.

Alat-alat yang digunakan dalam penelitian ini adalah alat-alat gelas, Spektrofotometer Serapan Atom, timbangan analitik, tanur (furnace), desikator, kertas saring whatmann dan cawan porselin. Adapun bahan yang digunakan dalam penelitian ini adalah $\mathrm{HNO}_{3}, \mathrm{H}_{2} \mathrm{SO}_{4}$, aseton, dan aquadest.

\section{Prosedur Kerja}

1. Proses Persiapan Sampel Rambut

Teknik pengambilan rambut yang digunakan adalah penyisiran dan pencabutan rambut menggunakan pinset steril (usahakan panjang rambut yang diambil $3 \mathrm{~cm}$ dari akar rambut). Pencabutan dilakukan dengan hati-hati agar tidak merusak helaian rambut. Sampel rambut diambil secukupnya (5-10 helai) dan dimasukkan ke dalam kantong plastic steril yang telah diberikan label nama/ kode sampel.

2. Proses Dektruksi Sampel Rambut 
Nova Florentina Ambarwati, Eka Margaretha Sinaga, Erdina Gultom / Jurnal Analis Kesehatan Klinikal Sains 9 (1) (2021)

Sebelum ditimbang cuci potongan rambut tersebut dengan akuades dan timbang sampel rambut sebanyak $2 \mathrm{mg}$, potong kecil-kecil berukuran $\pm 0,5 \mathrm{~cm}$ kemudian didestruksi dengan campuran 1:5 $\left(\mathrm{HClO}_{4}: \mathrm{HNO}_{3}\right)$, larutan dipanaskan di atas hot plate hingga larut semua dan membentuk cairan hampir jernih. Kemudian dinginkan di atas penangas air, lalu disaring dengan kertas saring Whatmann dan ukur filtrat yang diperoleh. (Chempublish, 2017)

3. Prosedur Pemeriksaan Spektrofotometer Masukkan seluruh filtrat ke dalam labu ukur $50 \mathrm{~mL}$, tambahkan dengan aquades hingga tanda batas. Setelah proses ini berjalan maka sampel siap di ukur dengan alat Spektrofotometer Serapan Atom (SSA) dengan panjang gelombang 283,3 nm.

\section{Rumus Perhitungan}

Konsentrasi sampel $\mathrm{Pb}(\mathrm{mg} / \mathrm{kg})=\frac{((D-E) \times F p \times V)}{W}$

Dimana :

D : Konsentrasi Sampel $\mu \mathrm{g} / \mathrm{L}$ dari hasil pembacan SSA

E : Konsentrasi Blanko $\mu \mathrm{g} / \mathrm{L}$ dari pembacaan SSA

Fp : Faktor Pengenceran

W : Bobot Sampel

\section{HASIL DAN PEMBAHASAN}

Adapun hasil yang diperoleh dapat dilihat pada Tabel 1.

Tabel 1. Data Hasil Uji Tingkat Keracunan Pb Pada Tukang Becak dan Pedagang Asongan (Data Primer)

\begin{tabular}{lcl}
\hline Kode sampel & Kadar Pb $(\mathbf{p p m})$ & $\begin{array}{l}\text { Tingkat Pencemaran Pb berdasarkan } \\
\text { WHO tahun } \mathbf{1 9 9 5}\end{array}$ \\
\hline TKB 1 & 16,690 & Tingkat pencemaran sedang $10-20 \mathrm{ppm}$ \\
TKB 2 & 4,533 & Tingkat pencemaran rendah $<10 \mathrm{ppm}$ \\
TKB 3 & 2,1384 & Tingkat pencemaran rendah $<10 \mathrm{ppm}$ \\
TKB 4 & 20,821 & Tingkat pencemaran tinggi $>20 \mathrm{ppm}$ \\
PDA 1 & 0,862 & Tingkat pencemaran rendah $<10 \mathrm{ppm}$ \\
PDA 2 & 10,697 & Tingkat pencemaran sedang $10-20 \mathrm{ppm}$ \\
PDA 3 & 0,998 & Tingkat pencemaran rendah $<10 \mathrm{ppm}$ \\
PDA 4 & 0,990 & Tingkat pencemaran rendah $<10 \mathrm{ppm}$ \\
\hline
\end{tabular}

Keterangan: TKB : Tukang Becak; PDA : Pedagang Asongan

Sedangkan pembahasan dari hasil penelitan dapat dilihat pada Gambar 1. 


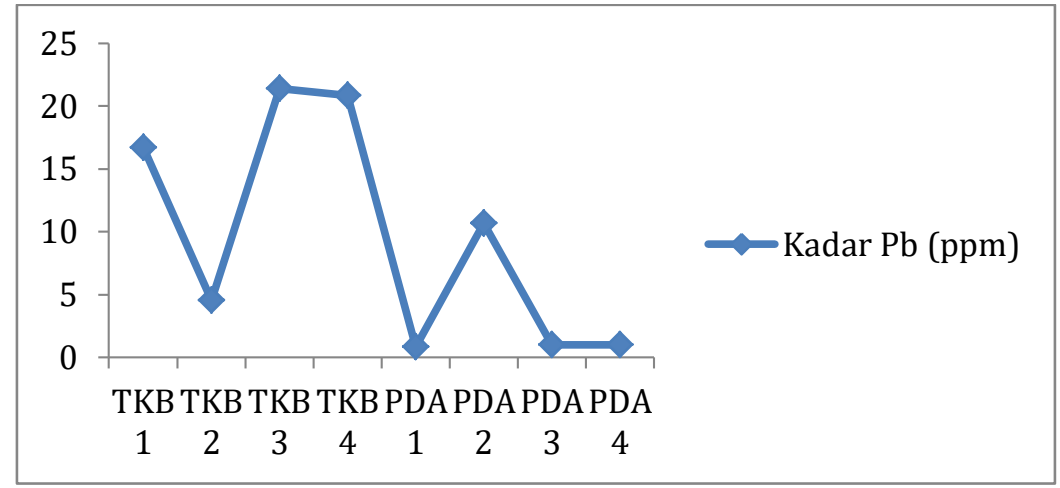

\section{Gambar 1 Grafik Kadar Pb (ppm) Pada Tukang Becak dan Pedagang Asongan dengan Metode SSA}

Dari hasil penelitian diperoleh bahwa seluruh sampel positif telah mengalami keracunan logam $\mathrm{Pb}$. Kadar $\mathrm{Pb}$ yang paling tinggi terdapat pada Tukang Becak dengan kode TKB 4 (20,821 ppm) tergolong tingkat keracunan tinggi, dan yang mengalami tingkat keracunan sedang sebanyak 2 yaitu Tukang Becak (TKB 1, kadar 16,690 ppm) dan Pedagang Asongan (PDA 2, kadar 10,697 ppm), sementara 5 lainnya tergolong tingkat keracunan rendah $(<10$ ppm).

Kemungkinan besar faktor yang menyebabkan hasil kadar $\mathrm{Pb}$ pada peneliti bernilai positif yaitu dari tingkat lama pekerjaan, faktor usia dan pola hidup dari para tukang becak dan pedagang asongan di sekitaran Jalan Kapten Muslim Medan. Hal ini terbukti pada tingkat keracunan $\mathrm{Pb}$ yang tergolong tinggi pada sampel kode TKB 4 (20,821 ppm), yang paling lama bekerja sebagai tukang becak yaitu sekitar 25 tahun. Selain itu, kebiasaannya yang sangat jarang menggunakan masker dan pola hidup yang kurang sehat. Sangat berbeda pada sampel PDA 1 $(0,862 \mathrm{ppm})$, yang usianya masih muda dan belum terlalu lama bekerja di lingkungan jalan raya sebagai pedagang asongan.

Alat pelindung diri merupakan alat yang memiliki fungsi melindungi individu dari pekerjaanya dan juga dapat melindungi pekerja dari bahaya ditempat kerja (Rijanto, 2011). Cahyono (2004) menjelaskan apabila Alat pelindung diri adalah alat keselamatan yang wajib dipakai oleh tenaga kerja jika berada pada tempat kerja dengan potensi bahaya. Peraturan Menteri Tenaga Kerja dan Transmigrasi No.Per.08/MEN/VII/ 2010 pasal 1 ayat (1), alat pelindung diri selanjutnya disingkat APD merupakan alat yang memiliki fungsi untuk melindungi pekerja yang gunanya membatasi sebagian atau seluruh tubuh dari potensi bahaya ditempat kerja (Suma'mur, 2009).

Paparan logam $\mathrm{Pb}$ dapat masuk ke dalam tubuh tukang becak dan pedagang asongan melalui udara dan makanan yang terkontaminasi $\mathrm{Pb}$. Keseharian pedagang asongan yang sangat sering berada di jalan, membuat mereka menjadi lebih rentan akan bahaya $\mathrm{Pb}$. Pada penelitian 
Nova Florentina Ambarwati, Eka Margaretha Sinaga, Erdina Gultom / Jurnal Analis Kesehatan Klinikal Sains 9 (1) (2021)

ini, masa kerja tukang becak dan pedagang asongan rata-rata minimal 5 tahun. Semakin lama masa kerjanya dan makin seringnya terpapar oleh timbal di udara, maka dapat diasumsikan bahwa semakin lama masa kerja pedagang asongan, maka kadar timbal dalam tubuh yang diwakili oleh rambut akan semakin tinggi.

Dalam penelitian yang dilakukan oleh schamramm (2008), rambut merupakan indikator yang telah berhasil digunakan dalam mengukur paparan internal maupun eksternal dari beberapa polutan organik terhalogenasi pada tubuh manusia. Posisi dan struktur khusus rambut memungkinkan untuk dilakukan penelitian yang mendalam terhadap paparan polutan jangka pendek dan jangka Panjang pada manusia, namun masih terdapat beberapa keterbatasan analisis rambut sebagai alat monitoring yang valid dalam menentukan resiko paparan polutan, antara lain : menentukan variasi dari komposisi rambut tiap individu, pengaruh usia, jenis kelamin, ras dan sebagainya.

Adapun bahaya logam berat $\mathrm{Pb}$ jika masuk kedalam tubuh dapat mengganggu kesehatan. Senyawa timbalnya masuk kedalam tubuh dapat mempengaruhi metabolisme tubuh, efek toksik logam dapat menghambat pembentukan $\mathrm{Hb}$, kerusakan pada sistem saraf, sistem urinaria, sistem reproduksi, sistem jantung, dan ginjal. Disamping itu pada wanita hamil logam $\mathrm{Pb}$ dapat melewati plasenta dan kemudian akan ikut masuk dalam sistem peredaran darah janin dan selanjutnya setelah bayi lahir $\mathrm{Pb}$ akan dikeluarkan Bersama air susu. Keracunan $\mathrm{Pb}$ dapat mempengaruhi sistem syaraf dan pertumbuhan anak-anak, keluhan sakit kepala, gelisah, gugup, lemas, mudah tersinggung, merupakan beberapa tanda yang mendahului efek keracunan sebelum terjadinya koma, kemudian kematian.

\section{KESIMPULAN}

Hasil pemeriksaan kadar timbal terhadap 4 sampel rambut tukang becak dan 4 sampel rambut pedagang asongan di sekitar Jalan Kapten Muslim diperoleh hasil seluruhnya positif mengandung logam $\mathrm{Pb}$.

\section{UCAPAN TERIMA KASIH}

Ucapan terima kasih disampaikan kepada pihak yang telah membantu dan bekerja sama demi kelancaran penelitian ini, yaitu kepada:

1. LPPM Universitas Sari Mutiara Indonesia Medan

2. Program Studi D3 Analis Kesehatan, Fakultas Farmasi \& Ilmu Kesehatan, Universitas Sari Mutiara Indonesia

3. Laboratorium Kesehatan Daerah Provinsi Sumatera Utara

\section{DAFTAR PUSTAKA}

Ardianto, D.2005. Deteksi Pencemaran Timah Hitam (Pb) dalam Darah, masyarakat yang terpajan timbal (Plumbun), Jurnal Kesehatan Lingkungan. Vol.2/No.1 
Anonim. 2012. Penyakit akibat kerja karena pajanan logam berat. Kementrian Kesehatan Republik Indonesia, Jakarta .

Cahyono, A.B. 2004. Keselamatan kerja bahan kimia di industri. Yogyakarta: Gadjahmada University Press.

Darma, Surya, 2005. Kadar Timbal Pada Darah Tukang Becak Mesin di Kota Siantar (11) 1. 31 35.http://repository.unhas.ac.id/bitsream/handle/12345678/JURNAL.pdf?sequence=1

Kusumawati.P.S Tang. U.M Nurhidayah. T, 2013 Hubungan Jumlah Kendaraan Bermotor dengan Emisi $\mathrm{CO}_{2}$

National Academy of Science. (2013). Occupational standards and guidelines for lead. Diakses dari https://www.ncbi.nlm.nih.gov/books/NBK206974/.

Palar, Heryando.2009. Pencemaran dan Toksikologi Logam Berat, : Jakarta Raylene, M Responden. 2008. Kulit, Rambut Kuku, Terjemah Benediktus Yohan, D.Lyrawati.

Peraturan Menteri Kesehatan Republik Indonesia nomor 70 tahun 2016 tentang Standar dan Persyaratan Kesehatan Lingkungan Kerja Industri.

Peraturan Menteri Tenaga Kerja dan Transmigrasi nomor 08 tahun 2010 tentang Alat Pelindung Diri.

Rijanto, B.B. 2011. Pedoman pencegahan kecelakaan. Jakarta: Mitra Wacana Media

Samsuar, M.Kanedi, Sherly, Ari, 2017, Analisa Kadar Timbal (Pb) Pada Rambut Tambal Ban di Sepanjang Jalan soekarno Hatta Kota Bandar Lampung, (8)1, 91-97.

Schamramm.2008. Kulit, Rambut, Kuku, Terjemahan Benediktus Yohan, D. Lyrawati

Shimadzu. 2009. Shimadzu Atomic Absoption Spectrophotometer AA-700 Series. Intruction Manual

Suma'mur P.K., 2009. Higiene perusahaan dan kesehatan kerja (HIPERKES). Jakarta: Sagung Seto.

Widowati Wahyu,dkk,2008.Efek Toksik Logam Yogyakarta : Andi. Uccoptaional Medicine.

Yamin, Moh Akhul,2009.Penurunan Kadar Timbal Pada Rambut Supir Bus Rute MojekertoSurabaya Dengan Peredaman Ekstrak Belimbing Wuluh (21)1, 21-29.

http://repo.stikesicmejbg.ac.id/289/KTI\%20MOH.\%20AKHUL\%20YAMIN\%20141310021.pd $\mathrm{f}$

Zuhraida, 2017. Pengaruh Lamanya Kerja Terhadap Kadar Timbal (Pb) Pada Tukang Becak Mesin di Pasar Ploso.(17)2, 22-25. http://fmipa.umri.ac.id/wpcontent/uploads/2016/06/nabila-I-deteksi-timah-dalam-darah.pdf 